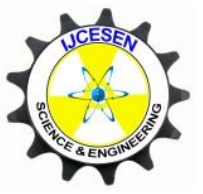

Copyright (C) IJCESEN
International Journal of Computational and

Experimental $\boldsymbol{S}$ cience and Engineering

(IJCESEN)

Vol. 5-No.1 (2019) pp. 1-9

http://dergipark.gov.tr/ijcesen

Research Article

\title{
Experimental Investigation of CSS Assisted by Gas-viscosity Reducer Co- Injection with Different Types of Wells and Heavy Oil
}

\author{
Wei ZHAO ${ }^{1,2 *}$, Huiqing LIU ${ }^{1,2}$, Chuan LU $^{3}$,Jing WANG ${ }^{1,2}$, Lin MENG ${ }^{4}$ and Ruihong \\ $\mathrm{ZHONG}^{1,2}$
}

\footnotetext{
${ }^{1}$ State Key Laboratory of Petroleum Resources and Engineering in China University of Petroleum, Beijing, China;

${ }^{2}$ MOE Key Laboratory of Petroleum Engineering in China University of Petroleum, Beijing, China;

${ }^{3}$ Research Institute of China National Offshore Oil Corporation, Beijing, China;

${ }^{4}$ Department of Chemical \& Petroleum Engineering, University of Calgary, Calgary, AB, Canada T2N1N4

* Corresponding Author : zhaoweicup@ 126.com

ORCID: 0000-0001-7439-4258
}

\section{$\underline{\text { Article Info: }}$}

DOI: $10.22399 /$ ijcesen. 485188

Received : 19 November 2018

Accepted : 12 December 2018

\section{Keywords}

Cyclic steam stimulation

EOR

Viscosity reducer

Non-condensable gas

\begin{abstract}
:
The efficiency of conventional thermal recovery methods is limited due to heat loss, steam overlapping and other factors. Steam injection assisted by various additives, such as no-condensable gas, solvent and surfactant, has proved to be an effective and beneficial method to improve thermal oil recovery. However, based on previous studies, systematic and comprehensive investigation of the compound system of gas-chemical agent and the application criteria is lacking. In this paper, a 3D physical model with different types of wells and heavy oil were designed. The additives consist of nitrogen and viscosity reducer (VR). Different injection fluid combinations (single gas, single VR and gas-VR coinjection), fluid injection configurations (gas-steam and gas+steam, VR-steam and VR+steam,) were applied to investigate the effects of the compound system on oil recovery, oil-steam ratio and oil production rate.

The results indicated that steam injection assisted by gas-VR performs effectively in enhancing the thermal recovery. The conclusions are drawn according to the variation curves of characteristic parameters. The effects of the compound system kept increasing the oil recovery after different injection patterns. Meanwhile, the cumulative SOR decreased after the corresponding processes sequentially. The distribution of temperature showed that gas-VR coinjection not only inhibited steam overlapping, which promoted the horizontal expansion of the steam chamber but also reduced the viscosity of heavy oil significantly. More oil was produced due to the gas expansion. In summary, this work provides a practical understanding of CSS assisted by gas-VR co-injection and optimization of the injection schemes for different types of reservoirs.
\end{abstract}

\section{Introduction}

With the decrease of conventional oil reserves and increase of the oil demand, heavy oil resources attract more attention of petroleum engineers. A series of thermal recovery techniques, such as cyclic steam stimulation (CSS), steam flooding, steam assisted gravity drainage (SAGD) are developed to enhance the heavy oil recovery $[1,11,18]$. However, the efficiency of conventional thermal recovery methods is limited due to heat loss, steam overlapping and other factors. Steam injection assisted by various additives, such as nocondensable gas, solvent and surfactant, has proved to be an effective and beneficial method to improve thermal oil recovery.

Non-condensate gas, such as nitrogen and $\mathrm{CO}_{2}$, were always used as a heat insulation agent $[2,9,17]$. It turned out to be beneficial for the EOR process. The mechanisms of steam injection assisted by no-condensate gas mainly include higher swelling effect, lower heat conductivity 
coefficient and interfacial-tension reduction $[6,9,15]$ by using $2-\mathrm{D}$ visualized model. The microscopic pictures displayed the oil displacement.

The chemical agents such as surfactant and solvent have also been used to assist the steam injection $[4,8,14]$. Due to low cost and stable properties, surfactant was applied to the process of thermal recovery, especially for viscosity reduction [7]. It has been shown that solvent additives can improve oil production rates with reduced steam injection [5,10]. However, most studies just showed the mechanism of gas and chemical agent separately $[3,12]$. Few systematic and comprehensive explanations were given to state the mechanism of the compound system of gas-chemical agent and the application conditions.

In this paper, a series of experiments were conducted to study the effect of gas and viscosityreducer injected with steam during the CSS stage. Different injection fluids, injection orders and injection patterns were investagated to study the effects of the compound system on oil recovery, oil-steam ratio and oil production rate.

\section{Experimental apparatus and procedures 2. 1 Experimental apparatus}

As shown in Figure 1, the setup for the experiments consisted of five subsystems: injection system, energy-supply system, temperature-pressure monitoring system, 3D physical simulation system, and fluid-data acquisition system. The injection system consisted of an ISCO pump, a steam generator, a nitrogen tank, a gas mass flow controller, a heating belt and a cylindrical tank. The 3D reservoir model was a stainless-steel container, with the dimensions of $36 \mathrm{~cm}$ in length, $36 \mathrm{~cm}$ in width and $21 \mathrm{~cm}$ in depth. The maximum tolerance pressure of the model was $3 \mathrm{Mpa}$. The $3 \mathrm{D}$ model could be used to simulate development with different types of the reservoirs and wells, different injection patterns and different injection fluids. The whole model was in the thermotank to maintain the constant temperature. The monitoring system included 36 temperature transducers and 8 pressure transducers. In the process of experiment, all these transducers were placed evenly in the model to detect the variation of the temperature and pressure with time. The data was recorded by the acquisition system. The energy-supply system was a cylindrical vessel filled with oil and compressed gas to provide energy for the physical model. A hand pump and a back-pressure regulator were installed in the outlet ensuring the stable production of the oil wells under reservoir pressure.
Comparing with the actual reservoir scale, the 3D physical model is relatively small. For the accuracy and reliability of experiments, the similarity criteria were established. Here, Pujol-Boberg's similarity criteria were used to calculate the designed parameters [13]. Table 1 shows the similarity criterion numbers of cyclic steam stimulation for heavy oil reservoir.

Table 1 Similarity criterion numbers of cyclic steam stimulation for heavy oil reservoir

\begin{tabular}{|c|c|c|}
\hline \multicolumn{3}{|c|}{ stimulation for heavy oil reservoir } \\
\hline $\begin{array}{c}\text { Pertical well spacing } \\
\text { or horizontal well } \\
\text { length }\end{array}$ & Similarity Criterion & Physical Meaning \\
\hline Permeability & $\frac{K \rho_{o} g t}{\phi\left(1-S_{w c}-S_{o r}\right) \mu_{o} L}$ & Geometric similarity \\
\hline Production time & $\frac{\alpha t}{L^{2}}$ & Dimensionless time \\
\hline $\begin{array}{c}\text { Production pressure } \\
\text { difference }\end{array}$ & $\frac{\Delta P}{\rho_{o} g L}$ & $\begin{array}{c}\text { Ratio of pressure and } \\
\text { gravity }\end{array}$ \\
\hline $\begin{array}{c}\text { Steam injection rate } \\
i_{s} t\end{array}$ & $\begin{array}{c}\text { Ratio of flow volume } \\
\text { and storage volume }\end{array}$ \\
\hline
\end{tabular}

In Table $1, \mathrm{~L}$ is vertical well spacing or horizontal well length, $\mathrm{m}$. $\mathrm{K}$ is permeability of prototype or simulation model, $10^{-3} \mu \mathrm{m}^{2} . \rho_{\mathrm{o}}$ is the oil density, $\mathrm{g} / \mathrm{cm}^{3} . \mathrm{g}$ is the gravitational acceleration, $\mathrm{m} / \mathrm{s}^{2} . \mathrm{t}$ is time, s. $\phi$ is the porosity of prototype or simulation model. $S_{w c}$ is the irreducible water saturation. $S_{\text {or }}$ is the residual oil saturation. $\mu_{\mathrm{o}}$ is the oil viscosity, $\mathrm{mPa} \cdot \mathrm{s} . \alpha$ is the thermal diffusion coefficient, $\mathrm{m}^{2} / \mathrm{s}$. $\Delta \mathrm{P}$ is the differential pressure of production, $\mathrm{MPa}$. $\mathrm{i}_{\mathrm{s}}$ is the steam injection rate. $\rho_{\mathrm{w}}$ is the water density, $\mathrm{g} / \mathrm{cm}^{3}$.

According to the similarity criteria, we can get the physical simulation parameters table based on the actual parameters of reservoir and internal parameters of 3D physical model, as shown in Table 2.

\section{2 Experimental procedures}

In this study, 3D physical model which included CSS in vertical well model with extra-heavy oil and CSS in horizontal well model with ultra-heavy oil were conducted. We named Set 1 and Set 2 for the $3 \mathrm{D}$ experiments, respectively. The processes were as follows:

Set 1: (1) The washed quartz sand and oil sample were prepared firstly. (2) The oil and the sand were mixed according to the designed proportion (volume ratio $=7: 13$ ). The clay was used to simulate the capping bed covering the oil layer. The vertical well was installed in the middle of the model. It was covered by the 300 meshes filter to prevent sand production. 
Table 2. Experimental parameters during different CSS stages.

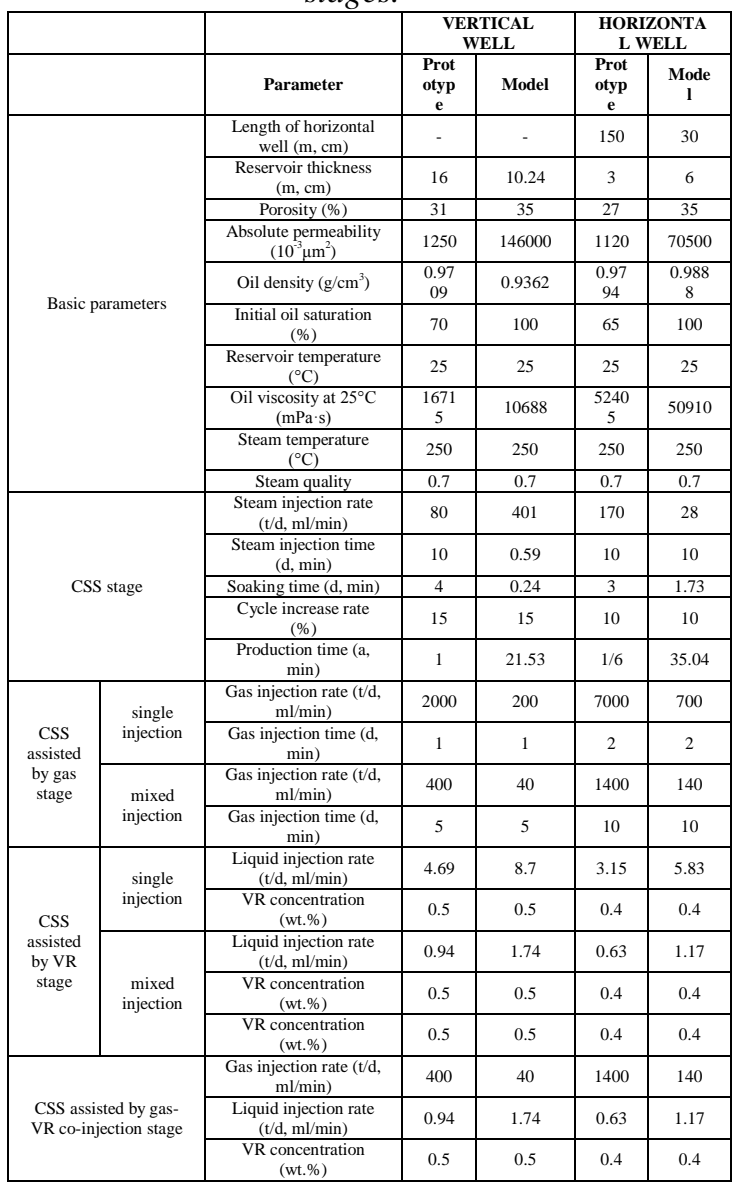

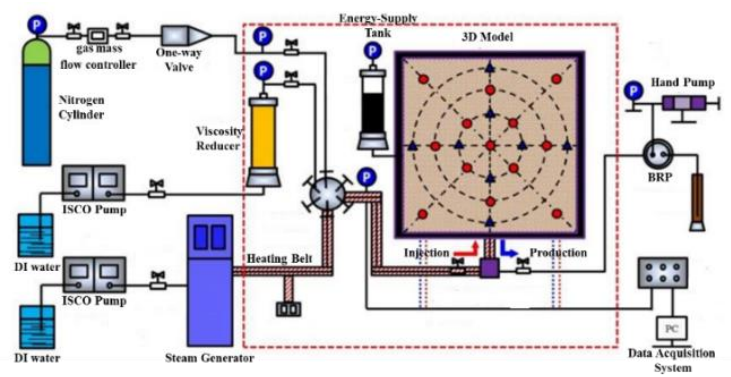

Figure 1. Schematic diagram of the experimental setup for the $3 D$ experiments

During the process of filling the model with oil sands, all the temperature and pressure transducers were placed in the designed locations. After the reservoir thickness reached the designed value $(10.24 \mathrm{~cm})$, the clay was used to fill the top capping bed (3) Check the tightness of the model to prevent oil leakage. The sealed model was pressurized by nitrogen under $3 \mathrm{MPa}$ for $12 \mathrm{~h}$. The leakage of the model was estimated based on the pressure variation. (4) According to the designed parameters, four displacement schemes were carried out. The produced fluid was collected by the measuring cylinder. When the oil-steam ratio is 0.1 , stop the experiments. Figure 2 shows the section diagram of the vertical model. It displays the

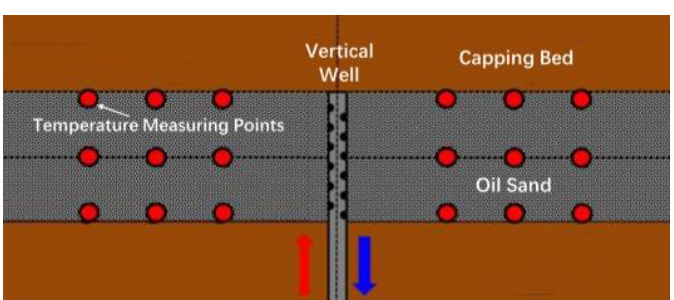

Figure 2 Section diagram of vertical-well model in extra heavy oil reservoir

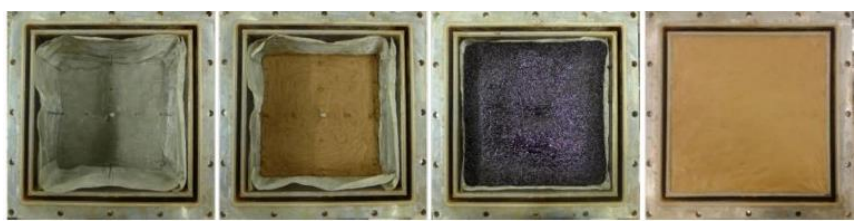

Figure 3. The preparation process of vertical-well model in extra heavy oil reservoir

internal situation of the model. Figure 3 shows the preparation process of vertical-well model in extra heavy oil reservoir.

Set 2: (1) The experimental preparation process was exactly the same with Set 1 except the oil samples and the well type. The oil was ultra-heavy oil and the well was horizontal well with the length of $30 \mathrm{~cm}$. (2) In this section, the reservoir thickness was $6 \mathrm{~cm}$. The filling and sealing process were also the same with Set 1. (3) There were also four patterns to be used as the designed parameters table. Figure 4 shows the section diagram of horizontal-well model. Figure 5 shows the preparation process of horizontal-well model in ultra-heavy oil reservoir. The location of the temperature measuring points was displayed visually.

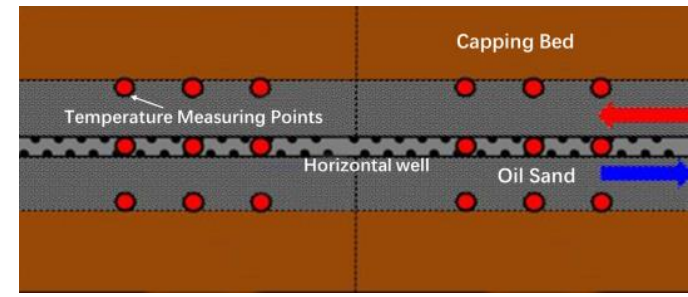

Figure 4. Section diagram of horizontal-well model in ultra-heavy oil reservoir

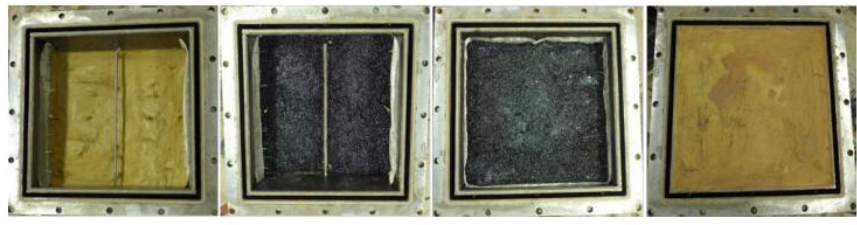

Figure 5. The preparation process of horizontal-well model in ultra-heavy oil reservoir

\section{Results and discussion}

\section{1 Experimental Results of Set 1}


CSS using vertical well in extra-heavy oil model was conducted in Set 1, different injection fluids, injection orders and injection patterns were applied to study the effect of EOR. The results were as follows:

\section{(1) CSS Stage}

As show in Figure 6, in the stage of CSS, the steam expanded and moved upwards under the action of gravity segregation which resulted in higher temperature at the top of the reservoir and lower temperature at the bottom of the reservoir. Figure $4 \mathrm{a}$ and $4 \mathrm{~b}$ showed the direction of the section area. Both of these represented the same situation of CSS stage at the same time, just in different directions. With the increase of CSS cycles, the steam overlapping became more severe, leading to the stronger heterogeneity of vertical and horizontal expansion. At the end of CSS, the temperature of top, middle and bottom layer were $68.1^{\circ} \mathrm{C}, 50.5^{\circ} \mathrm{C}$ and $44.5^{\circ} \mathrm{C}$, respectively. It can be seen that the temperature difference was obvious.
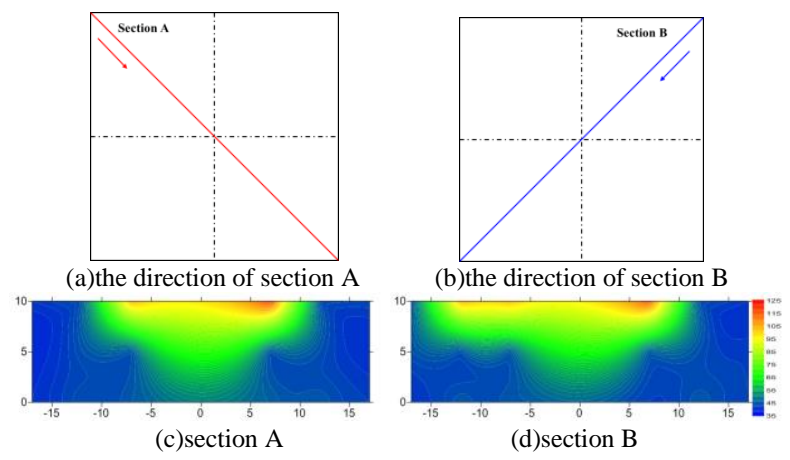

Figure 6. Vertical distribution of temperature at the end of CSS stage

Figure 7 shows the variation curves of characteristic parameters including oil production rate and cumulative oil-steam ratio during CSS stage. At the initial stage of CSS, the oil saturation around the well was high. Under the condition of high-temperature steam, the heavy oil volume expanded, and the viscosity reduced which led to a high production rate. However, with the increase of CSS cycles, the oil production rate decreased and then remained stable. According to Figure 5, it can be seen that the stable cumulative oil-steam ratio was 0.16 .

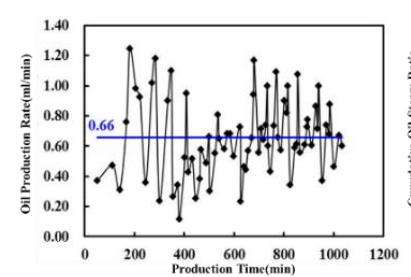

(a) Oil production rate curve

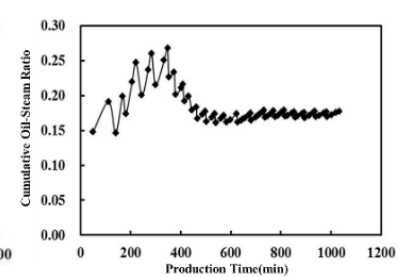

(b) Cumulative oil-steam ratio curve
Figure 7. Variation curves of characteristic parameters during CSS stage

\section{(2) CSS Assisted by Gas Stage}

Single injection process: according to the designed scheme, single injection was first applied with nitrogen injection first and then steam injection. The fluid-acquisition-data indicated that the incremental oil recovery factor was $6.19 \%$. Figure 6(a) showed that the temperature of top, middle and bottom layer were $64.9^{\circ} \mathrm{C}, 53.5^{\circ} \mathrm{C}$ and $46.5^{\circ} \mathrm{C}$, respectively. Compared with the temperature of CSS stage, it can be seen that the temperature of middle and bottom layers increased, on the contrary, the top layer temperature decreased. It indicated that nitrogen injection inhibited the steam overlapping phenomenon because the gas reached the top layer firstly and pushed the steam down which promoted the vertical expansion of the steam chamber. However, the effect on the horizontal expansion of steam chamber was not significant.

Mixed injection process: after the single injection process was finished, the mixed injection process was conducted. The total recovery was $26.85 \%$, increased by $5.39 \%$ than last process. As show in Figure 7(b), the heating area in horizontal direction increased obviously and the steam overlapping was further restrained compared with Figure 7(a). The reason was that the mixture of $\mathrm{N}_{2}$ and steam accelerated the process of heating, which was easier for $\mathrm{N}_{2}$ and steam to migrate in the porous media resulting in migration distance increased. Finally, the mixed injection process promoted the horizontal expansion of the steam chamber.

Figure 8 shows the variation curves of characteristic parameters during CCS assisted by $\mathrm{N}_{2}$. For the single injection process, the average oil production rate was $1.61 \mathrm{ml} / \mathrm{min}$ and the cumulative oil-steam ratio reached 0.35 . Also, the average oil production rate decreased to $1.32 \mathrm{ml} / \mathrm{min}$ but was also high and the cumulative oil-steam ratio remained stable. The results indicated that single injection was more beneficial to the vertical expansion of the steam chamber and had a stronger effect on the drainage of $\mathrm{N}_{2}$. Besides, mixed injection reduced the heat loss around the well and increased the lateral expansion distance and sweep area.

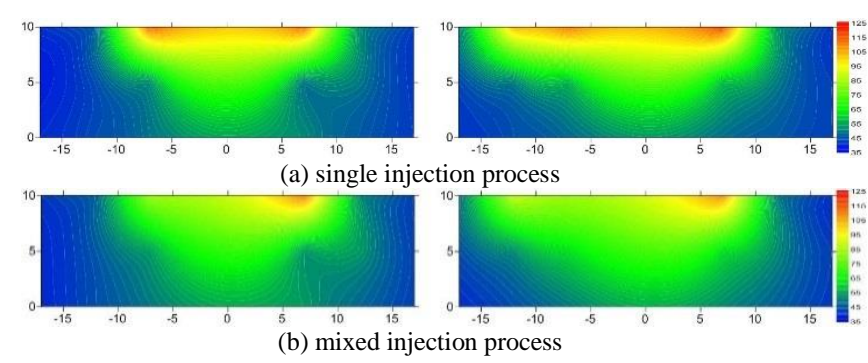

Figure 8. Vertical distribution of temperature at the end of CSS assisted by gas 

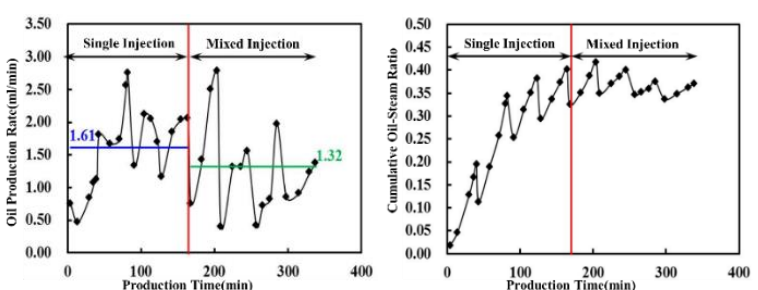

(a) Oil production rate curve (b) Cumulative oil-steam ratio curve

Figure 9. Variation curves of characteristic parameters during CSS assisted by N2 stage

\section{(3) CSS Assisted by VR stage}

Single injection process: in this process, VR was injected before steam injection. At the end of single injection process, the final recovery reached $31.98 \%$ which was $5.13 \%$ higher than the process with gas stage. Figure 8(a) showed that, compared with the N2 stage, the total sweep area decreased especially at the bottom and middle layers. The main reason was that the VR solution increased the water storage around the well and prevented the steam contacting with heavy oil directly which resulted in higher condensing rate of steam and heating loss.

Mixed injection process: in this process, the mixture of steam and VR was injected. As shown in Figure10(b), the temperature of the top, middle and bottom layer were $69.6^{\circ} \mathrm{C}, 54.6^{\circ} \mathrm{C}$ and $44.8^{\circ} \mathrm{C}$, respectively. The total average temperature and heating area were larger than that of single injection process which indicated the heating loss was lower than the single injection process.

Figure 11 shows the variation curves of characteristic parameters during CCS assisted by VR. The oil rates of two injection patterns were $1.46 \mathrm{ml} / \mathrm{min}$ and $1.52 \mathrm{ml} / \mathrm{min}$, respectively, both of which were higher than that of mixed injection of $\mathrm{N}_{2}$-Steam. Meanwhile, the cumulative oil-steam ratio remained stable at 0.3 . Under the combined effect of VR and high-temperature steam, the viscosity of extra-heavy oil was notably decreased leading to higher mobility. At the same time, the emulsification of VR was significant, which resulted in a higher oil production rate.

\section{(4) CSS Assisted by Gas-VR co-injection stage}

In this stage, the $\mathrm{N}_{2}$-VR co-injection with steam was conducted.

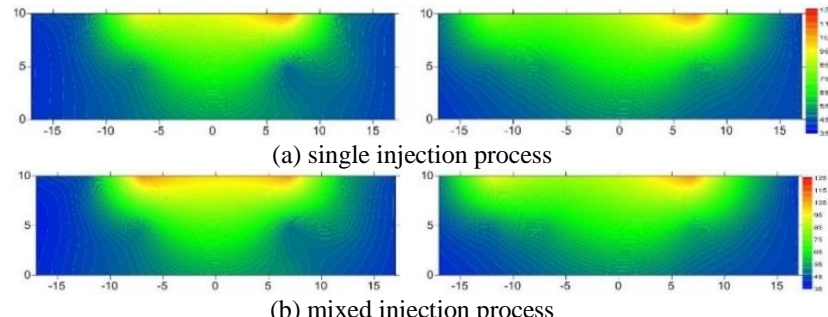

Figure 10. Vertical distribution of temperature at the end process of CSS assisted by VR
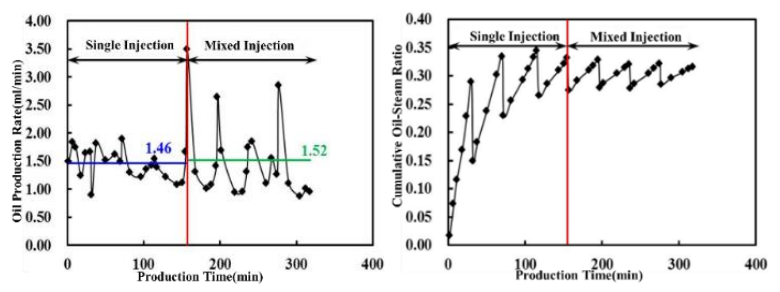

$\begin{array}{ll}\text { (a) Oil production rate curve } & \text { (b) Cumulative oil-steam ratio curve }\end{array}$

Figure 11. Variation curves of characteristic parameters during the process of CSS assisted by VR stage

The final recovery was $40.89 \%$, increased by $4.29 \%$ over the last stage. According to Figure 12, the temperature of the top layer was lower than that of VR injection stage. In addition, the emulsion phenomenon was obvious in the photomicrograph of production liquid which illustrated the effect of VR still played a role. Also, the oil production rate and cumulative oil-steam ratio showed a stable trend, further explaining that more oil was produced under the combined effect of gas and VR even after many cycles.
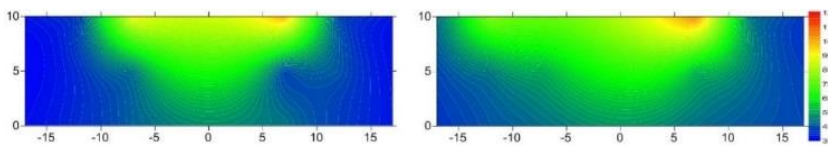

Figure 12 Vertical distribution of temperature at the end process of CSS assisted by Gas-VR co-injection stage

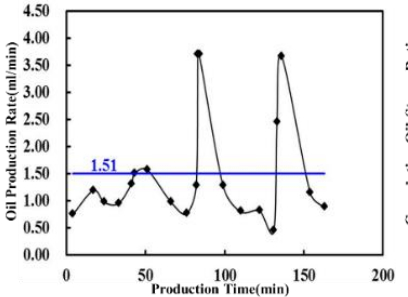

(a) Oil production rate curve

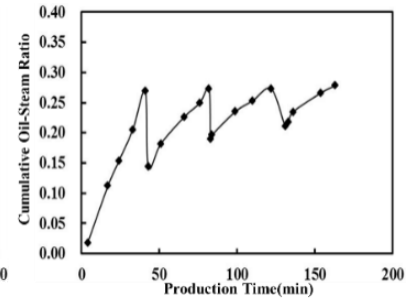

(b) Cumulative oil-steam ratio curve
Figure 13. Variation curves of characteristic parameters during CSS assisted by Gas-VR co-injection stage

Figure 14 displays the variation curves of characteristic parameters of different liquid injection for Set 1 . It can be seen that the additive of gas and VR can obviously increase the oil production rate. The oil recovery was improved significantly after the CSS process, the oil recovery of which was just $15.26 \%$. The incremental oil recovery was $11.58 \%, 9.76 \%, 4.29 \%$ after gas injection, VR injection and gas-VR co-injection in turn and the final recovery was $40.89 \%$. All of this shows that gas-VR co-injection not only inhibited steam overlapping, which promoted the horizontal expansion of the steam chamber but also reduced the viscosity of heavy oil significantly. More oil was produced due to the gas expansion energy.

\subsection{Experimental Results of Set 2}

CSS using horizontal well in ultra-heavy oil model 


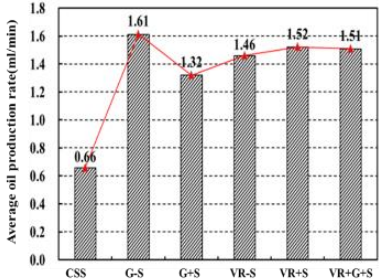

(a)Average oil production rate

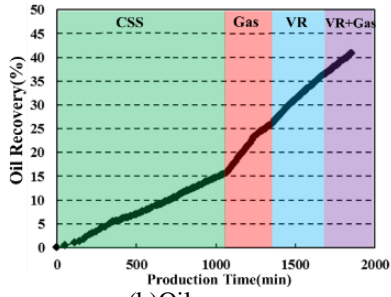

(b)Oil recovery
Figure 14. Variation curves of characteristic parameters for Set 1 process

were conducted in Set 2. The injection patterns were similar with Set 1 . The details were as follows:

\section{(1) CSS Stage}

In this process, the final recovery of CSS was $17.28 \%$. According to the plane and the vertical distribution of temperature, as shown in Figure 15 and 16 , it can be seen that steam overlapping was serious, the temperature of the top layer was higher than that of the other two layers. Meanwhile, the shape of the temperature field was conical. The reason was that steam flow in the horizontal well was variable mass flow resulting in different injection rate in the different position of the horizontal well, and the heating loss was also different due to the long length of the well. The final results were displayed in the temperature field map. The sweep area of heel was higher than that of toe.

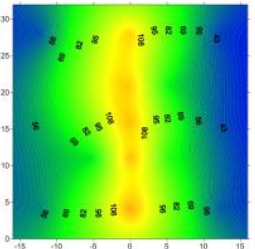

(a) top layer

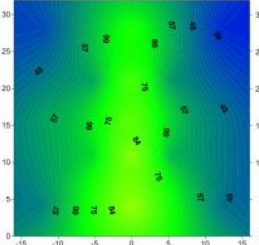

(2) middle layer

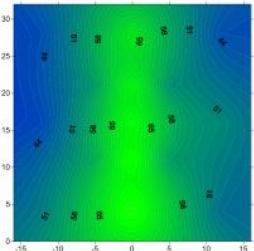

(3) bottom layer
Figure 15. Plane distribution of temperature at the end process of CSS stage
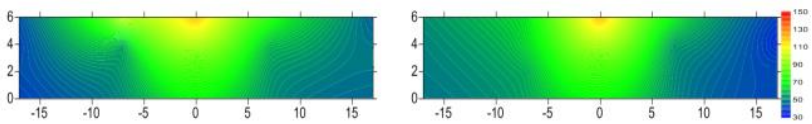

Figure 16. Vertical distribution of temperature at the end process of CSS stage

As shown in Figure 17, in the early stage of CSS, the thermal efficiency was high leading to a high oil production rate because of the low water storage near the well. At the end stage of CSS, the oil production rate and the cumulative oil-steam ratio decreased due to the low thermal efficiency.

\section{(2) CSS Assisted by Gas Stage}

Single injection process: The gas $\left(\mathrm{N}_{2}\right)$ was first injected before the steam injection. The total recovery at the end of the process was $27.49 \%$, which increased by $10.21 \%$.
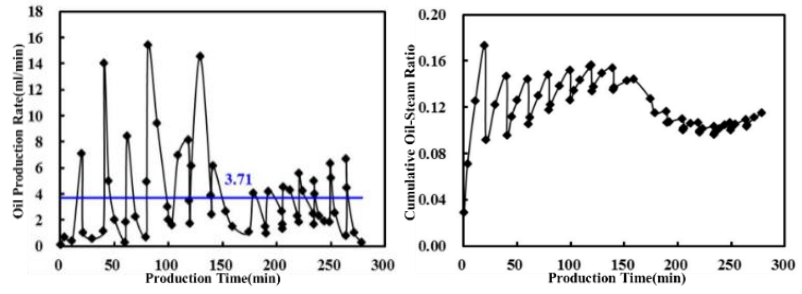

(a) Oil production rate curve

(b) Cumulative oil-steam ratio curve

Figure 17. Variation curves of characteristic parameters during CSS stage in Set 2

The average pressure increased from $148 \mathrm{kPa}$ to $309 \mathrm{kPa}$ leading to the high steam injection pressure and thermal efficiency. $\mathrm{N}_{2}$ gathering at the top layer pushed the steam down and improved the temperature of the middle and bottom layers. This scenario was more obvious at the beginning of the displacement.

Mixed injection process: The recovery was $37.87 \%$ which increased by $10.38 \%$ in this process. As shown in Figure 18(b), the heating area increased along the direction of the wings, especially for the bottom layer. The average temperature of the bottom layer in this process was $57.7^{\circ} \mathrm{C}$ which was $5.3^{\circ} \mathrm{C}$ higher than that in the single injection process.
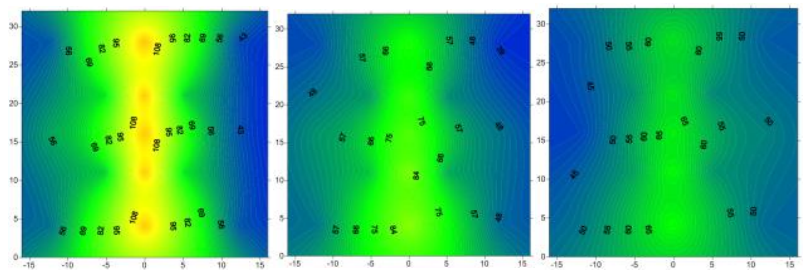

(a) Single injection process
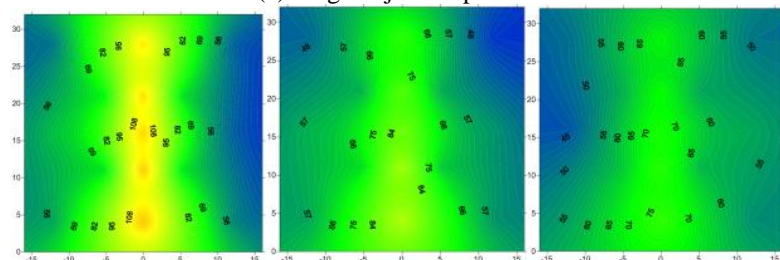

(b) Mixed injection process

Figure 18. Plane distribution of temperature at the end process of CSS assisted by gas stage in Set 2
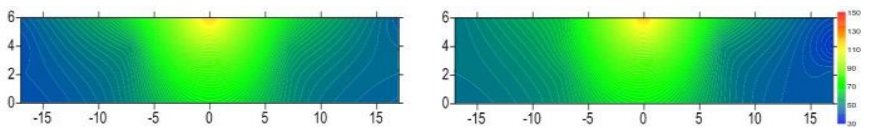

(a) single injection process

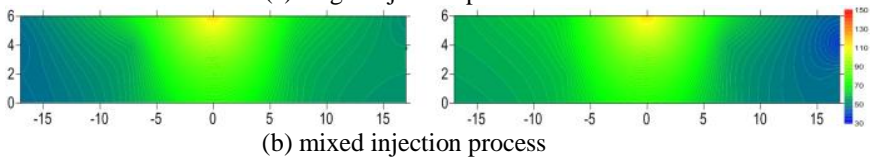

Figure 19. Vertical distribution of temperature at the end process of CSS assisted by gas stage in Set 2

And we can also see that the temperature difference between the heel and the toe became smaller and the heat distribution was more uniform. As shown in Figure 20, the average oil production rate for single injection process was $8.89 \mathrm{ml} / \mathrm{min}$, and it was 
$5.05 \mathrm{ml} / \mathrm{min}$ for mixed injection process, both of which were higher than that of CSS process. The cumulative oil-steam ratio remained as 0.25 at the end of the stage. It demonstrated that the addition of nitrogen was an effective way to improve the energy of the reservoir and oil displacement, which was similar to the result of Set 1.

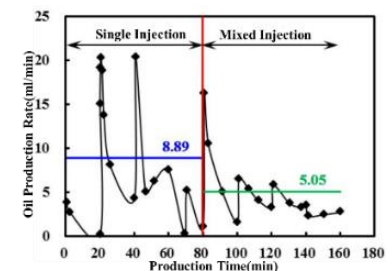

(a) Oil production rate curve

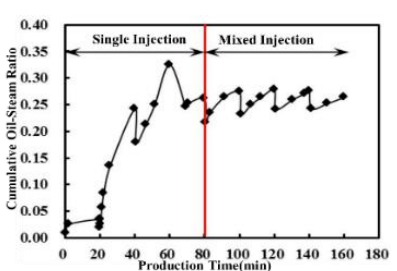

(b) Cumulative oil-steam ratio curve
Figure 20. Variation curves of characteristic parameters during CSS assisted by gas stage in Set 2

\section{(3) CSS Assisted by VR stage}

Single injection process: VR was first injected before the steam injection. The recovery was $42.87 \%$, which increased by $5.00 \%$ compared to the previous stage. As shown in Figure 21(a), compared with the previous stage of $\mathrm{N}_{2}$, the temperature and the steam chamber decreased. The reason is that the injection volume of VR was smaller than that of $\mathrm{N}_{2}$, so the pressurizing effect was not obvious. In addition, the water storage around the well increased leading to a higher heating loss. Thus, the thermal efficiency was affected.

Mixed injection process: the final recovery was $46.45 \%$ at the end of this process. Compared with the previous process, the average temperature of the top, middle and bottom layer were $67.6^{\circ} \mathrm{C}, 61.7^{\circ} \mathrm{C}$ and $58.2^{\circ} \mathrm{C}$, respectively, which increased dramatically. It indicated that the mixed injection process reduced the heating loss. The horizontal expansion was more effective and uniform according to Figure 22. As shown in Figure 23, the oil production rate of single injection was $5.29 \mathrm{ml} / \mathrm{min}$, slightly higher than that of mixed injection. Considering the difference of heating area, it indicated that the degree of reaction between VR and heavy oil for single injection process increased, and it was important for the large water storage situation around the well after many cycles of CSS. In the mixed injection process, the sweep area did not increase but the oil production rate maintained as a high value which indicated that VR improved the displacement efficiency of near wellbore area.

\section{(4) CSS Assisted by Gas-VR Co-injection Stage}

In this process, $\mathrm{N}_{2}, \mathrm{VR}$ and steam were injected into the model simultaneously. At the end of the stage, the recovery was $59.29 \%$, which increased
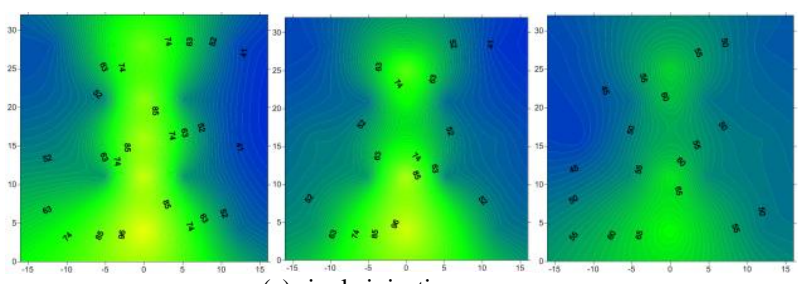

(a) single injection proces
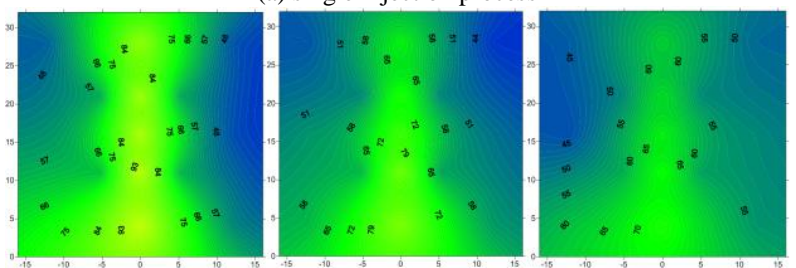

(b) mixed injection process

Figure 21. Plane distribution of temperature at the end process of CSS assisted by VR stage in Set 2
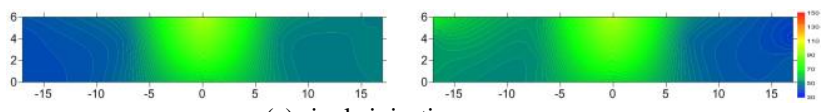

(a) single injection process

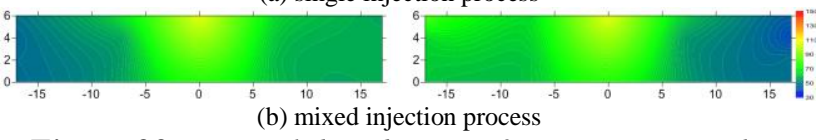

Figure 22. Vertical distribution of temperature at the end process of CSS assisted by VR stage in Set 2

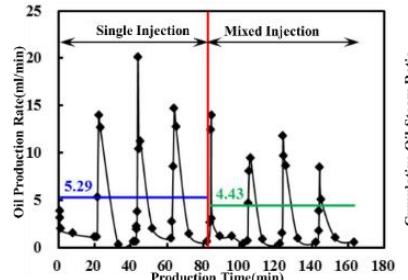

(a) Oil production rate curve

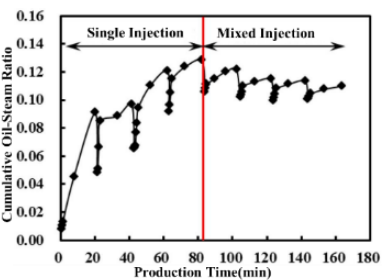

(b) Cumulative oil-steam ratio curve
Figure 23 Variation curves of characteristic parameters during CSS assisted by VR stage in Set 2

by $9.42 \%$. At the end of this process, according to the distribution of temperature, the average temperature was high and the sweep area expanded to the sides of the model. The conical shape caused by the heating loss and variable mass flow was not obvious, especially for the top and middle layers. This phenomenon was more clearly in the vertical distribution of temperature, as shown in Figure 25. It indicated that gas-VR co-injection inhibited steam overlap, promoting the horizontal expansion of the steam chamber, and reduced the viscosity of heavy oil significantly. The gas expansion pushed more oil out of the reservoir. Both the effect of VR and N2 were fully-developed. Figure 26 shows the variation curves of characteristic parameters of different liquid injection for Set 2. It indicated the average oil production rate and oil recovery of different injection stage. It can be seen that the additive of gas can improve the oil production rate significantly which was contributed to the suppliedenergy effect of the injection gas. 


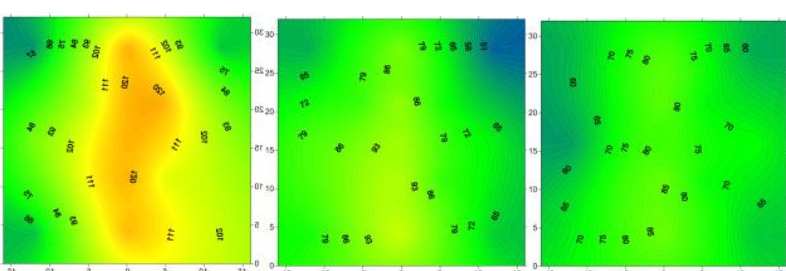

Figure 24. Plane distribution of temperature at the end process of CSS assisted by $N_{2}-V R$ Co-injection stage in Set 2
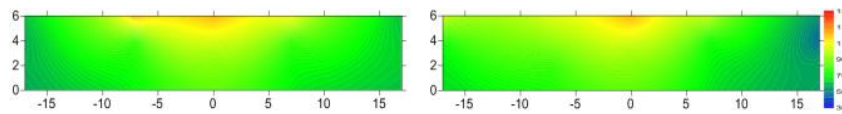

Figure 25. Vertical distribution of temperature at the end process of CSS assisted by N2-VR Co-injection stage in Set 2

For the thin reservoirs of heavy oil with horizontal well, the horizontal expansion of the steam chamber was the main contradiction affecting the development effect. The added gas helped the horizontal expansion of steam. Based on the produced liquid, oil-in-water $(\mathrm{O} / \mathrm{W})$ emulsions generated under the combined-effect of gas and VR were more dispersive, compared with the single injection. According to Figure 26(b), the oil recovery of CSS was $17.28 \%$, the incremental oil recoveries were $20.59 \%, 8.57 \%, 8.8 \%$ after gas injection, VR injection and gas-VR co-injection in turn above and the final recovery was $55.29 \%$. The effects of the compound system still worked and increased the oil recovery after different injection patterns.

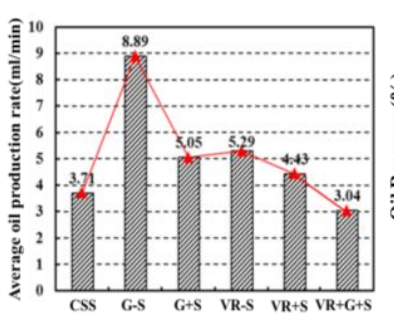

(a) Average oil production rate

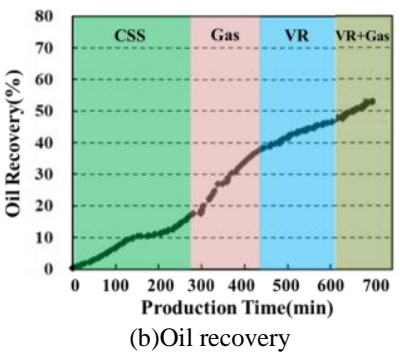

(b)Oil recovery

Figure 26. Variation curves of characteristic parameters for Set 1 process

\section{Conclusions}

A series of experiments were conducted to investigate the effect of gas and VR injected with steam during the CSS stage. The conclusions are as follows:

- The compressibility of nitrogen can improve the reservoir energy. Due to the gravity segregation, the nitrogen can occupy the upper section which inhibits the steam overlapping. Also, it can promote the vertical expansion of the steam chamber and increase the swept area.
- The injected VR solution can reduce the viscosity of heavy oil and change the scenario of the trapped oil near wellbore area especially. $\mathrm{O} / \mathrm{W}$ emulsion is produced when the mobility gets stronger.

- It is proved that steam injection assisted by gas-VR is more beneficial to enhance the thermal recovery.

- Different injection orders have an impact on the recovery and sweep situation.

\section{Acknowledgement}

This work was financially supported by the National Science and Technology Major Project of China(2016ZX05031003004)

\section{Nomenclature}

CSS cyclic steam simulation,

EOR enhanced oil recovery,

SOR steam-oil ratio,

VR viscosity reducer,

ISCO the type of pump used in the experiments.

\section{References}

[1] C.A. Connally, Jr., J.E. Marberry. Steam Flood Pilot, Nacatoch Sand-Troy Field, Arkansas. SPE-4758MS presented at Improved Oil Recovery Symposium of the Society of Petroleum Engineers of AIME: 22-24 April, (1974) Tulsa, Okla, USA. DOI: http://dx.doi.org/10.2118/4758-MS

[2] Cai, Y. C., et al. A study on the technology of steam hot water - nitrogen compound drive after steam channeling in steam flooding. Applied Mechanics \& Materials, 316-317, 854-859. (2013) DOI: 10.4028/www.scientific.net/AMM.316-317.854.

[3] Decker, A. M., \& Flock, D. L. Thermal stability and application of emulsion composed blocking agents for steamflooding. Journal of Canadian Petroleum Technology, 27(4), 69-78.

[4] Erincik, M. Z., Qi, P., Balhoff, M. T., \& Pope, G. A. (2017, October 9). New Method to Reduce Residual Oil Saturation by Polymer Flooding. Society of Petroleum Engineers. DOI:10.2118/187230-MS

[5] Gates, I. D., \& Chakrabarty, N. Design of the steam and solvent injection strategy in expanding-solvent steam-assisted gravity drainage. Journal of Canadian Petroleum Technology, 47(9), (2008), 12 20. DOI: https://doi.org/10.2118/08-09-12-CS

[6] Jha, K. N. (1986). A laboratory study of heavy oil recovery with carbon dioxide. Journal of Canadian Petroleum Technology, 25(2), 54-63. (1988) DOI: https://doi.org/10.2118/SS-85-04.

[7] Liu, Q., Dong, M., \& Ma, S. Alkaline surfactant flood potential in western Canadian heavy oil reservoirs. SPE/doe Symposium on Improved Oil Recovery. (2006) DOI: https://doi.org/10.2118/99791-MS 
[8] Lu, C., Liu, H., Liu, Q., Lu, K., \& Wang, L. Research on the Effect of Non-Condensable Gas and Viscosity Reducer for Better SAGD Performance. (2014) DOI: https://doi.org/10.2118/170026-MS.

[9] Lu, C., Liu, H., \& Zhao, W. Visualized study of displacement mechanisms by injecting viscosity reducer and non-condensable gas to assist steam injection. Journal of the Energy Institute, 90(1). (2015)

DOI: https://doi.org/10.1016/j.joei.2015.10.005

[10] Lu, C., Liu, H., Zhao, W., Lu, K., Liu, Y., \& Tian, J., et al. Experimental investigation of in-situ emulsion formation to improve viscous-oil recovery in steam-injection process assisted by viscosity reducer. Spe Journal, 22(1). (2017) DOI: https://doi.org/10.2118/181759-PA.

[11] Lyu, X., et al., "Visualized study of thermochemistry assisted steam flooding to improve oil recovery in heavy oil reservoir with glass micromodels." Fuel 218: 118-126. DOI: https://doi.org/10.1016/j.fuel.2018.01.007

[12] Miller, J. S., \& Jones, R. A. A Laboratory Study to Determine Physical Characteristics of Heavy Oil After CO2 Saturation. SPE/DOE Enhanced Oil Recovery Symposium. Society of Petroleum Engineers. (1981) DOI: https://doi.org/10.2118/9789-MS

[13] Pujol L and Boberg T C. Scaling accuracy of laboratory steam flooding models. Paper SPE 4191 Presented at the SPE California Regional Meeting, Bakersfield, California. (1972) DOI: https://doi.org/10.2118/4191-MS

[14] Qi, P., Ehrenfried, D. H., Koh, H., \& Balhoff, M. T. Reduction of Residual Oil Saturation in Sandstone Cores by Use of Viscoelastic Polymers. Society of Petroleum Engineers (2017). DOI:10.2118/179689PA

[15] Rojas, G. A. Dynamics of subcritical co2/brine floods for heavy-oil recovery. SPE Reservoir Engineering, 3(1), (1988) 35-44. DOI: https://doi.org/10.2118/13598-PA.

[16] S.R. Upreti, A. Lohi, R.A. Kapadia, et al., Vapor extraction of heavy oil and bitumen: a review, Energy Fuels 21 (3) (2007) 1562-1574. DOI: 10.1021/ef060341j

[17] Wang, Y., Ge, J. J., Jiang, P., Zhang, G. C., \& Du, Y. Mechanism and Feasibility Study of Nitrogen Assisted Cyclic Steam Stimulation for Ultra-Heavy Oil Reservoir. (2013) DOI: https://doi.org/10.2118/165212-MS

[18] Zhang Xia, Zhang Xialin. Optimization Study of Production-Injection Ratio for Steam Flooding. IPTC-16458-MS presented at International Petroleum Technology Conference, (2013)26-28 March, Beijing, China. DOI: http://dx.doi.org/10.2523/16458-MS 